\title{
INOVAÇÃO E ESTRATÉGIAS DIGITAIS: ESTUDO COMPARATIVO DO CASO THE NEW YORK TIMES COM A REVISTA EXAME
}

\author{
Innovation and digital strategies: comparative case study of The New York \\ Times with Exame magazine
}

\begin{abstract}
Innovación y estrategias digitales: estudio comparativo del caso The New York Times con la revista Exame
\end{abstract}

\author{
Egle Müller Spinelli \\ Professora da Escola Superior de Propaganda e Marketing (ESPM-SP) \\ egle.spinelli@espm.br \\ Mariana Crosio Benvenido \\ Mestre pela Escola Superior de Propaganda e Marketing (ESPM-SP) \\ mbenvenido@gmail.com
}

\section{Resumo}

Este estudo investiga se ocorrem aplicações de inovações na revista Exame com base nas estratégias digitais pontuadas no relatório do The New York Times (NYT) intitulado "Journalism That Stands Apart" e publicado em 2017, que propôs metas para 2020 conforme três categorias: reportagem, redação e rotina de trabalho. O objetivo é compreender se a Exame utiliza ações semelhantes às implementadas no NYT para gerar processos inovadores em três instâncias pertencentes ao Manual de Oslo: organizacional, marketing e tecnológica. Como apontamentos finais infere-se que a Exame reproduz algumas estratégias do NYT, executa processos diferenciados dos existentes no mercado nacional de revistas informativas, mas ainda precisa investir em inovações no ambiente digital.

Palavras-chave: Inovação. Estratégias Digitais. Jornalismo.

\begin{abstract}
This paper investigates if there are applications of innovations in Exame magazine based on the digital strategies outlined in The New York Times (NYT) report called "Journalism that stands apart" (2017), which proposed targets for 2020 according to three categories: reporting, writing and work routine. The objective is to understand if Exame uses similar actions to those implemented in the NYT to generate innovative processes in three instances belonging to Oslo Manual: organizational, marketing and technological. As final notes, it is inferred that Exame reproduces some strategies of the NYT, performs processes differentiated from those existing in the national market of informative magazines, but still needs to invest in innovations in the digital environment.
\end{abstract}

Key words: Innovation. Digital Strategies. Journalism. 


\section{Resumen}

Este artículo investiga si ocurren aplicaciones de innovaciones en la revista Examen con base en las estrategias digitales puntuadas en el informe del The New York Times (NYT) intitulado "Journalism That Stands Apart" (2017), que propone metas para 2020 según tres categorías que pertence a Manual de Oslo (2006): reportaje, redacción y rutina de trabajo. El objetivo es comprender si la Exame utiliza acciones similares a las implementadas en el NYT para generar procesos innovadores en tres instancias: organización, marketing y tecnología. Como apuntes finales se desprende que la Exame reproduce estrategias del NYT y ejecuta procesos innovadores diferenciados de los que ya existen en el mercado nacional, pero necesita invertir en innovaciones en el entorno digital.

Palabras clave: Innovación. Estrategias Digitales. Periodismo.

\section{INTRODUÇÃO}

Desde o século passado, as empresas de comunicação enfrentam dificuldades e mudanças significativas que afetam suas estruturas, geradas por novos concorrentes, processos de rentabilização e alcance do público. A internet e o desenvolvimento tecnológico possibilitam outras formas de produção e distribuição da informação, impelindo as organizações jornalísticas a inovar em produtos digitais e buscar alternativas de modelos de negócio. Na perspectiva de Grueskin, Seave e Graves (2011), a mídia tradicional altera suas estratégias para se aproximar do universo digital. Os autores compreendem que essas empresas foram, aos poucos, se desvinculando do modelo industrial das décadas passadas com o objetivo de se sustentarem diante das transformações do setor. Com isso, um dos principais desafios do século XXI para os veículos de comunicação é descobrir caminhos para inovar e transformar o antigo negócio em algo que agregue valor para diversos atores envolvidos: jornalistas, investidores, anunciantes e consumidores (PICARD, 2013).

Costa (2014) argumenta que as empresas jornalísticas precisam mudar o posicionamento e buscar alternativas para gerar novas receitas. Isso se deve principalmente pela perda de espaço do impresso para o digital com a migração dos leitores para a web. Dados do Instituto Verificador de Comunicação (IVC) apontam que de 2015 para 2017, a circulação das revistas jornalísticas no Brasil apresentou uma queda de 44,72\%. Neste cenário, a inovação é um dos primeiros passos para alavancar o jornalismo na era digital. $\mathrm{Na}$ visão de Boczkowski (2004), as organizações noticiosas que se reconfigurarem pensando em inovar estarão aptas para atender aos interesses do público. Um exemplo de empresa jornalística que busca estratégias inovadoras é o The New York Times (NYT), por redefinir constantemente ações para expandir as experiências no digital. 
Segundo Fontoura (2015), o NYT alterou o processo de produção do impresso e passou a distribuir o conteúdo em plataformas digitais, que foram responsáveis por mudanças estruturais na organização. A ascensão do meio on-line e a capacidade de criar oportunidades intensificou o desenvolvimento de tecnologias e novos produtos para a empresa. Em nota divulgada pelo NYT (PEISER, 2018), o periódico teve um aumento de 25\% em assinaturas digitais no primeiro trimestre de 2018. O jornal conquistou 139 mil novos assinantes, totalizando 2,783 milhões de assinaturas digitais. Os novos assinantes provocaram o crescimento de 3,28\% das receitas do $N Y T$, que alcançou US\$ 4,14 milhões no primeiro trimestre de 2018. O investimento em inovação e produtos digitais é um dos fatores que contribuíram para os resultados alcançados pelo jornal. Para Leonhardt et al. (2017), não existe um modelo de negócio que sustente $100 \%$ a redação do $N Y T$, sendo necessário acelerar as inovações. Portanto, as organizações midiáticas precisam aceitar as transformações e produzir, constantemente, estratégias digitais para desenvolver produtos para o consumo da informação.

Wolf (2009) enfatiza a existência de publicações que são referências para outros veículos. De acordo com o autor, nos Estados Unidos, essa função é desempenhada pelo NYT e pelo The Washington Post. Portanto, devido ao crescimento digital do NYT e partindo do pressuposto de Wolf, o jornal foi selecionado como modelo no desenvolvimento de estratégias digitais para este estudo.

Para compreender a realidade digital, o NYT produziu três relatórios: Innovation Report (2014), Our Path Forward (2015) e Journalism That Stands Apart (2017). Essas publicações são importantes para a estruturação da pesquisa, uma vez que focam nas questões da inovação para o desenvolvimento de estratégias digitais. As estratégias indicadas no relatório Journalism That Stands Apart (2017) foram aplicadas neste estudo com o intuito de verificar se a revista Exame incorpora ou cria inovações em seus produtos. Para isso, foi feito um paralelo entre as inovações do periódico com a atuação da revista a partir do conceito de inovação definido no Manual de Oslo $^{1}$ (2006) e com base nas categorias nele descritas (organizacional, marketing e tecnológica).

\footnotetext{
${ }^{1}$ Editado (1990) pela Organização para a Cooperação e Desenvolvimento Econômico (OCDE), O Manual de Oslo tem "o objetivo de orientar e padronizar conceitos, metodologias e construção de estatísticas e indicadores de pesquisa de P\&D de países industrializados" (OCDE, 2006, p. 9). A publicação determina escalas de inovações e suas características, sendo considerado fonte internacional de diretrizes para a coleta e uso de dados sobre as atividades de inovação na indústria. Foi traduzido para o português pela Finep, em 2004.
} 
A Exame foi escolhida como corpus $^{2}$ deste estudo devido à relevância no segmento de revistas de negócio e pelo desenvolvimento de estratégias de inovação. De acordo com o seu mídia kit ${ }^{3}$, é a revista de negócios mais lida por presidentes de empresas, sendo a maior e mais influente publicação de negócios do país. Ela foi considerada a revista mais admirada do ano na edição de 2017 da pesquisa Veículos mais Admirados, realizada pelo Meio \& Mensagem (VEÍCULOS..., 2016). Outro critério de escolha foi sua presença em diferentes plataformas: site, aplicativo e revista, promovendo mais possibilidades de inovação. Por exemplo, o aplicativo Exame Hoje, lançado em abril de 2016. O formato apresentado nunca foi implementado em uma publicação nacional. O aplicativo oferece conteúdo exclusivo, com matérias que não estão disponíveis no site ou na revista. Diante das iniciativas de inovação em um veículo tradicional, a Exame se qualificou como objeto deste artigo.

É importante ressaltar que o NYT e a Exame se encontram em mercados diferentes. Sabe-se das limitações em basear casos de sucesso internacionais com o mercado brasileiro, pois cada país possui suas particularidades sociais, econômicas, políticas e culturais, além de estabelecerem dinâmicas específicas para produção, circulação e consumo de informação conforme as necessidades do mercado. Porém, o que se observa nesta pesquisa são as categorias pontuadas no relatório Journalism That Stands Apart (2017), junto às categorias (tecnológica, marketing e organizacional) de inovação definidas no Manual de Oslo. O relatório serve como referência para a definição de instâncias que sustentam a pesquisa para a compreensão de possíveis aplicações inovadoras na revista. O Brasil ainda precisa percorrer um longo caminho para a concepção de inovações e não existem empresas que sistematizaram a inovação como os relatórios de $N Y T$.

Diante desses apontamentos, o objetivo deste estudo é compreender se a Exame utiliza ações semelhantes às implementadas no $N Y T$ para gerar processos inovadores em três instâncias: organizacional, marketing e tecnológica.

O artigo está ancorado em uma pesquisa exploratória de caráter qualitativo, métodos que promovem mais familiaridade com o problema e, normalmente, envolvem levantamento bibliográfico, entrevistas e análise de exemplos com a finalidade de esclarecer e modificar conceitos (GIL, 1994). Para este estudo, foram desenvolvidos quatro percursos

\footnotetext{
${ }^{2} \mathrm{O}$ corpus faz parte de uma pesquisa maior, sendo um recorte da dissertação de Mestrado Novos modelos de negócio nas organizações jornalísticas: o processo de inovação e criação de valor da revista Exame (2018). No momento da pesquisa, a Exame estava passando por recorrentes transformações em seu modelo de negócio, além de implementar estratégias digitais para criar novos processos, produtos e serviços.

${ }^{3}$ Editora Abril. Mídia Kit Revista Exame 2018. São Paulo, 2018. Disponível em:

<http://publiabril.abril.com.br/marcas/exame/plataformas/revista-impressa>. Acesso em:10 fev. 2018.
} 
metodológicos: 1) revisão bibliográfica com sustentação dos conceitos teóricos abordados como inovação e estratégias digitais, para elencar os pontos de cruzamento de análise a partir das três categorias propostas no relatório Journalism That Stands Apart (2017) do NYT reportagem, redação e rotina de trabalho - e das três instâncias de caráter inovador propostas pelo Manual de Oslo (OCDE, 2006) - organizacional, marketing e tecnológica (processos e produtos); 2) entrevistas semiestruturadas com profissionais da Exame (dois editores, um repórter e um redator) utilizadas como instrumentos básicos para a coleta de dados e captação de informação e experiência dos entrevistados. Decidiu-se escolher profissionais de dentro da revista para responder as questões abordadas. Uma vez que o artigo não tem a intenção de trazer opinião de fora, mas ver como esses profissionais percebem a inovação; 3) monitoramento e coleta de dados das plataformas da Exame (revista, site e aplicativo), entre os dias 14 de novembro de 2017 a 28 de novembro de 2017, para identificar exemplos práticos envolvendo o uso de inovações na revista; 4) análise, descrição e interpretação dos dados referentes às estratégias digitais desenvolvidas pela Exame e a comparação com as ações inovadoras propostas no relatório Journalism That Stands Apart (2017).

\section{INOVAÇÃO NO JORNALISMO}

A inovação é caracterizada como uma atividade humana, um modelo amplo e interdisciplinar e utilizada por empresas para alavancar modelos de negócio (CAPRINO, 2008). Na visão de Pavlik (2011), a inovação é a chave para a viabilidade das notícias na era digital com processo de escolhas de novas formas e abordagens às práticas de mídias. As inovações proporcionam a reestruturação das estratégias organizacionais, envolvendo a cadeia de valor do jornalismo tradicional para o digital. Na maioria das vezes, a mídia impressa apresenta resistência em inovar, e isso dificulta a transição para um novo modelo de negócio. "Os meios de comunicação tradicionais têm sido lentos para integrar a tecnologia em suas práticas de negócios ou monetizá-la para criar novas formas de conteúdo" (PAVLIK, 2013, p. 184). Gynnild (2014) afirma que as inovações são adaptadas para o universo do jornalismo. As empresas de mídia para se reinventar precisam buscar profissionais de outras áreas para incrementar habilidades no processo de produção, circulação e consumo de notícia, aliando-se com diferentes setores. De acordo com a autora, tais parcerias refletem em um novo posicionamento do jornalista, pois o profissional passa a apropriar-se de competências de outras áreas e, assim, atualiza suas rotinas de produção. 
O Manual de Oslo (OCDE, 2006) aponta três principais categorias de inovação que podem ser aplicadas nas empresas jornalísticas: inovação tecnológica, inovação organizacional e inovação de marketing. A inovação tecnológica, segundo Franciscato (2010), é a interação da tecnologia com a sociedade. Segundo ele, "A inovação tecnológica indica, pelo termo, uma vinculação a procedimentos que envolvem geração ou aplicação das tecnologias no jornalismo" (p. 12). O Manual de Oslo (OCDE, 2006) divide a inovação tecnológica em duas categorias: inovação de processo e de produto. A inovação de produto se caracteriza pela introdução de um novo produto ou serviço. Já a inovação de processo é a implantação de um novo método de produção como forma de reduzir custos, melhorar a qualidade, solucionar um problema ou monitoração do produto. Barañano (2005) explica que os processos tecnológicos podem aumentar a produtividade e a competitividade entre as empresas. Para a autora, o sucesso da inovação tecnológica depende da força de trabalho, estratégias, alianças e da organização interna da empresa.

A inovação de marketing, de acordo com o Manual de Oslo, se caracteriza pela “implementação de um novo método de marketing com mudanças significativas na concepção do produto ou em sua embalagem, no posicionamento, em sua promoção ou na fixação de preços" (OCDE, 2006, p. 59). Na perspectiva de Spinelli (2017, p. 67), “a inovação nessa área é primordial para as empresas jornalísticas repensarem estratégias na criação de ações, produtos e serviços que vão ao encontro das necessidades específicas dos consumidores nas diferentes plataformas e redes digitais". As inovações de marketing referem-se a "[...] novos métodos de marketing, incluindo mudanças no design do produto e na embalagem, na promoção do produto e sua colocação, e em métodos de estabelecimento de preços de bens e de serviços" (OCDE, 2006, p. 23).

Para Higgins (1995), essa inovação proporciona uma melhoria significativa em elementos do marketing que se destacam pela diferenciação, como no caso de novas estratégias envolvendo produtos, promoção, preço ou distribuição. Naidoo (2010) considera que a inovação de marketing se relaciona com a sobrevivência da empresa. Segundo o autor, quando uma organização enfrenta uma crise (interna ou externa), precisa desenvolver uma nova estratégia de marketing capaz de promover vantagem competitiva para a marca. Portanto, as organizações jornalísticas que quiserem se destacar no mercado, devem pensar em ações inovadoras de marketing que produzam alternativas para os desafios enfrentados no ambiente digital. 
A inovação organizacional é a implementação de um novo método de organização. Spinelli (2017) enfatiza que essa inovação representa novos modelos de gestão e práticas de negócio, envolvendo diferentes players como fornecedores, funcionários, distribuidores, leitores e anunciantes. Segundo o Manual de Oslo (OCDE, 2006), a inovação organizacional é caracterizada pela criação de uma nova estrutura no funcionamento e procedimentos de trabalho de uma empresa, visando a melhoria do seu desempenho. Christensen (2012, p. 72) ressalta que "a estrutura da organização e o meio como seus grupos aprendem a trabalhar em conjunto afetam a maneira como a empresa pode ou não projetar novos produtos". Para implementar a inovação organizacional é preciso modificar a estrutura organizacional existente.

Boczkowski (2004) considera que a inovação na mídia se desenvolve por meio da relação entre a tecnologia, a comunicação e a organização. Nessa mesma perspectiva, Souza (2017) infere que as empresas inovadoras alteram a rotina de trabalho, consequentemente, afetando a estrutura organizacional.

Podemos observar que as empresas jornalísticas têm adotado mudanças relevantes em seus modos de produção, nos formatos e linguagens de seus produtos, nas estratégias de circulação das notícias e também na composição profissional de seus jornalistas (SOUZA, 2017, p. 147).

Küng (2013) explica os avanços tecnológico intensificam a necessidade de inovações nas empresas noticiosas. Segundo a autora, a inovação altera a estrutura e as decisões estratégicas, uma vez que a criação de conteúdo e a tecnologia se fundem. No entanto, Küng afirma que as empresas jornalísticas ainda não possuem total domínio sobre as mudanças organizacionais provenientes do ambiente digital. Na perspectiva da autora, é necessário o conhecimento do modelo de negócio para aplicar uma inovação.

Em um mundo ideal, a inovação deve trazer crescimento. E tecnologias digitais trouxeram crescimento. Eles criaram novas maneiras de alcançar, conectar-se e envolver-se com o público. Essas audiências estão se envolvendo com entusiasmo e investindo pesadamente em gadgets e infraestrutura que permitem que isso ocorra (KÜNG, 2013, p. 9).

Baumann (2013) aponta que a inovação, as estratégias e a estrutura organizacional são componentes interligados. De acordo com a autora, a estrutura organizacional das empresas jornalísticas se otimizou, com equipes reduzidas e mais flexíveis. 
As organizações de mídia têm se tornado cada vez mais multidimensionais, com camadas sobrepostas de estruturas primárias, secundárias e até mesmo terciárias, impulsionadas por configurações baseadas em projetos, produtos e no mercado, através de clientes que exigem experiências de mídia inovadoras e individualizadas (BAUMANN, 2013, p. 90).

\section{ESTRATÉGIAS INOVADORAS DO THE NEW YORK TIMES}

O NYT faz parte da The New York Times Company, que além do conteúdo impresso, também é proprietária do NYTimes.com e de outros produtos e serviços oferecidos pela organização. Nafría (2017) considera o NYT um exemplo de como uma corporação midiática pode incentivar estratégias de inovação no ambiente digital para manter o jornalismo como um valor indispensável à empresa e à sociedade. "Para que o jornal continue a desempenhar um papel relevante no negócio do Times, é necessário adaptar sua fórmula aos novos tempos, ao novo ambiente, a novas formas de consumir informações” (NAFRÍA, 2017, p. 20).

Segundo Fontoura (2015), o NYT alterou o processo de produção do impresso e distribuiu o conteúdo por meio de diversas plataformas digitais. A ascensão do meio on-line intensificou o desenvolvimento de tecnologias e novos produtos para a empresa. Em janeiro de 2017, foi divulgado o relatório Journalism That Stands Apart (LEONHARDT et al., 2017), abordando as mudanças e metas do NYT para 2020. O relatório indica que o crescimento digital proporcionou um lucro operacional de 29 milhões de dólares no primeiro trimestre de 2017, contra 27,9 milhões no mesmo período de 2016, apenas por receita digital. No total, o lucro on-line anual é de 500 milhões de dólares, com 1,5 milhões de assinantes no digital e 1 milhão no impresso. NafrÍa (2017) afirma que em 2016, o faturamento do NYT se dividia em: $56,6 \%$ dos leitores, $37,3 \%$ da publicidade e $6,1 \%$ de outras fontes.

De acordo com Nafría (2017), em 2005, o periódico apresentava uma média de vendas de 1,7 milhões de edições impressas aos domingos; já em 2016, o número caiu para 1,08 milhões. Segundo dados divulgados pelo periódico em maio de 2018 (PEISER, 2018), o NYT teve um total de 308 mil assinaturas digitais no primeiro trimestre de 2017. No mesmo período, em 2018, o jornal totalizou 2,783 milhões assinaturas digitais. Esse crescimento é resultado das estratégias desenvolvidas pelo $N Y T$ com foco na inovação e no cenário digital. Com isso, o relatório propôs metas (Quadro 1) para 2020, que foram divididas em três categorias: reportagem, redação e rotina de trabalho. 


\begin{tabular}{|c|c|c|}
\hline Categoria & & Estratégias \\
\hline \multirow{4}{*}{ Reportagem } & Reportagens visuais & $\begin{array}{l}\text { - Aumentar o número de reportagens com estímulo visual. } \\
\text { - Apostar em conteúdo multimídias e narrativas visuais digitais. }\end{array}$ \\
\hline & $\begin{array}{l}\text { Uso de ferramentas } \\
\text { digitais }\end{array}$ & $\begin{array}{l}\text { - } \quad \text { Aumentar o uso de ferramentas digitais. } \\
\text { - } \quad \text { Utilizar chamadas rápidas (briefings e newsletters). }\end{array}$ \\
\hline & $\begin{array}{l}\text { Nova abordagem para } \\
\text { serviços jornalísticos }\end{array}$ & $\begin{array}{l}\text { - Aumentar o uso de áudios e vídeos na produção de conteúdo. } \\
\text { - Utilizar uma linguagem jornalística mais criativa. }\end{array}$ \\
\hline & $\begin{array}{l}\text { Leitores como parte da } \\
\text { reportagem }\end{array}$ & - Maior participação e engajamento dos leitores nas reportagens. \\
\hline \multirow{4}{*}{ Redação } & $\begin{array}{l}\text { Treinamento para os } \\
\text { funcionários }\end{array}$ & $\begin{array}{l}\text { - Capacitar os jornalistas para desenvolverem e produzirem no } \\
\text { ambiente digital. }\end{array}$ \\
\hline & $\begin{array}{l}\text { Acelerar a contração } \\
\text { de jornalistas }\end{array}$ & $\begin{array}{l}\text { - Aumentar o ritmo de contratação, especialmente em áreas } \\
\text { fragilizadas como jornalistas visuais. }\end{array}$ \\
\hline & Diversidade na redação & $\begin{array}{l}\text { Proporcionar variedade de pessoas e ideias para aprimorar a } \\
\text { audiência. } \\
\text { - Expandir a audiência internacionalmente e atrair leitores jovens. } \\
\text { - Ter uma equipe diversificada. }\end{array}$ \\
\hline & $\begin{array}{l}\text { Repensar o trabalho do } \\
\text { freelancer }\end{array}$ & $\begin{array}{l}\text { - Reestruturar o trabalho do freelance estendendo para outras } \\
\text { áreas. }\end{array}$ \\
\hline \multirow{6}{*}{$\begin{array}{l}\text { Rotina de } \\
\text { trabalho }\end{array}$} & Visão compartilhada & $\begin{array}{l}\text { - Garantir que os funcionários tenham clareza do todo da } \\
\text { empresa, nas três áreas: jornalistas, audiências e operações. }\end{array}$ \\
\hline & $\begin{array}{l}\text { Estabelecer metas e } \\
\text { acompanhar o } \\
\text { progresso }\end{array}$ & $\begin{array}{l}\text { - } \quad \text { Estabelecer metas tangíveis no ecossistema digital. } \\
\text { - Verificar e acompanhar o desenvolvimento das metas. } \\
\text { - } \quad \text { Compreender o objetivo das metas. }\end{array}$ \\
\hline & Redefinir o sucesso & $\begin{array}{l}\text { - Pensar em um modelo baseado em assinaturas e tempo de } \\
\text { permanência no site, evitando o pageview como a única métrica. }\end{array}$ \\
\hline & Edição mais conceitual & $\begin{array}{l}\text { - Apresentar uma edição mais conceitual dos editores nos textos } \\
\text { dos jornalistas, melhorando a qualidade das reportagens. }\end{array}$ \\
\hline & $\begin{array}{l}\text { Redação trabalhando } \\
\text { em conjunto }\end{array}$ & $\begin{array}{l}\text { - Aumentar o trabalho em conjunto entre as diferentes áreas da } \\
\text { redação para melhor qualidade dos conteúdos produzidos. }\end{array}$ \\
\hline & $\begin{array}{l}\text { Reduzir o papel } \\
\text { dominante do } \\
\text { jornalismo impresso }\end{array}$ & $\begin{array}{l}\text { - Valorizar e reorganizar a produção para o digital, uma vez que o } \\
\text { ritmo do impresso atrasa o desenvolvimento de estratégias. } \\
\text { - Colocar o digital na frente do impresso. } \\
\text { - Aceitar as mudanças do ecossistema digital. }\end{array}$ \\
\hline
\end{tabular}

Quadro 1 - Estratégias digitais do NYT para 2020

Fonte: Elaborado pelas autoras com base no Journalism That Stands Apart (2017).

No aspecto da reportagem, observa-se que o NYT está focado na inserção de elementos visuais. O relatório considera que textos longos podem ser substituídos por gráficos, imagens e outros recursos que despertam a atenção dos leitores pela visualização atraente e acessível do conteúdo. Nafría (2017) afirma que essa estratégia facilita a compreensão da informação e proporciona uma melhor experiência para os leitores, especialmente nos dispositivos móveis.

No âmbito da redação, as metas apontadas no relatório indicam a capacidade de preparar profissionais, na maioria das vezes, para produções audiovisuais. O principal ponto é a organização da equipe para o desenvolvimento de um trabalho a partir da compreensão de quem é a audiência. 
Devemos alinhar as habilidades de nossos jornalistas com as demandas de nossas ambições jornalísticas. Precisamos de uma equipe que torne o The Times ainda mais um destino de leitor do que é hoje, capaz de atrair um público maior e capaz de se tornar uma fonte ainda mais influente de notícias e informações (LEONHARDT et al., 2017).

Nafría (2017) argumenta que existe uma crescente contratação de jornalistas no NYT com o objetivo de trazer profissionais aptos a responderem às exigências do ambiente digital. Além disso, é interessante focar no treinamento para a capacitação dos jornalistas. A questão da rotina de trabalho engloba o funcionamento interno e a necessidade de aproximação entre diferentes áreas. O relatório aponta a importância de pensar digitalmente, desvinculando-se do formato tradicional. "Devemos reorganizar a redação para refletir nosso presente e futuro digital em vez do nosso legado impresso" (LEONHARDT et al., 2017). O NYT tem como estratégia aumentar o engajamento dos leitores. "O Times não procura cliques fáceis para gerar visualizações de páginas sem valor. Seu objetivo é manter o usuário leal para gastar o máximo de tempo possível consumindo seu produto" (NAFRÍA, 2017, p. 07). Para isso acontecer, o autor afirma que é necessário que os profissionais tenham clareza sobre a missão e o valor que a empresa pretende transmitir.

As metas do NYT para 2020 levam em consideração a sustentação do periódico no ecossistema digital e as necessidades da audiência. O relatório Journalism That Stands Apart (2017) descreve estratégias inovadoras que, neste estudo, foram classificadas conforme as categorias de inovação (tecnológica, marketing e organizacional) propostas pelo Manual de Oslo (Quadro 2). Essa classificação permite elencar aplicações que serão utilizadas como base para a análise na revista Exame.

\begin{tabular}{|c|c|c|}
\hline Inovação Tecnológica & Inovação de Marketing & Inovação Organizacional \\
\hline $\begin{array}{l}\text { - } \text { Reportagens mais visuais. } \\
\text { - } \quad \text { Ferramentas digitais. } \\
\text { - } \quad \text { Leitores como parte da } \\
\text { reportagem. } \\
\text { - } \quad \text { Edição mais conceitual. } \\
\text { - } \\
\text { Reduzir o papel } \\
\text { dominante do jornalismo } \\
\text { impresso. }\end{array}$ & $\begin{array}{l}\text { - Novas abordagens para } \\
\text { serviços jornalísticos. } \\
\text { - Estabelecer metas e } \\
\text { acompanhar processo. } \\
\text { - } \quad \text { Redefinir o sucesso. }\end{array}$ & 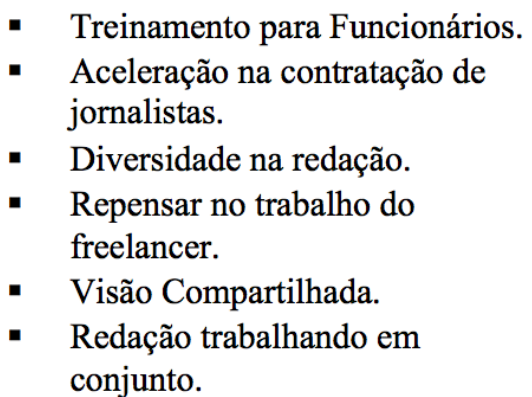 \\
\hline
\end{tabular}

Quadro 2 - Classificação das estratégias de inovação do The New York Times

Fonte: Elaborado pelas autoras. 


\section{APLICAÇÕES DAS ESTRATÉGIAS DO THE NEW YORK TIMES NO CASO DA}

\section{REVISTA EXAME}

As ações do $N Y T$ servem como parâmetro para a análise das estratégias digitais na revista Exame. Neste sentido, este estudo investiga se existem aplicações de ações inovadoras de um case de sucesso internacional em uma publicação nacional. A análise a seguir (Quadro 3) apresenta a relação entre as duas organizações jornalísticas e a classificação das inovações realizadas.

\begin{tabular}{|c|c|c|}
\hline $\begin{array}{l}\text { Estratégias e Inovações } \\
\text { desenvolvidas pelo } N Y T\end{array}$ & $\begin{array}{l}\text { Aplicação das estratégias na } \\
\text { Exame }\end{array}$ & Categoria de Inovação \\
\hline $\begin{array}{l}\text { - Reportagens mais visuais e } \\
\text { uso de ferramentas digitais }\end{array}$ & $\begin{array}{l}\text { - Reportagens em vídeos áudios } \\
\text { - Produção de newsletters }\end{array}$ & $\begin{array}{ll}\text { - } & \text { Tecnológica } \\
\text { Organizacional }\end{array}$ \\
\hline $\begin{array}{l}\text { Leitores como parte da } \\
\text { reportagem }\end{array}$ & $\begin{array}{l}\text { - Canal Seu Dinheiro } \\
\text { - Cartas e e-mails }\end{array}$ & $\begin{array}{ll}\text { - Organizacional } \\
\text { Tecnológica } \\
\end{array}$ \\
\hline $\begin{array}{l}\text { Novas abordagens para } \\
\text { produtos jornalísticos }\end{array}$ & - Aplicativo Exame Hoje & $\begin{array}{ll}\text { - } & \text { Tecnológica } \\
\text { - } & \text { Marketing } \\
\text { - } & \text { Organizacional } \\
\end{array}$ \\
\hline - Redefinir o sucesso & - Modelo de assinatura & - $\quad$ Marketing \\
\hline $\begin{array}{l}\text { - Redação trabalhando em } \\
\text { conjunto }\end{array}$ & $\begin{array}{l}\text { - Redação trabalhando } \\
\text { separadamente }\end{array}$ & - Organizacional \\
\hline
\end{tabular}

Quadro 3 - Estratégias e inovações NYT × Exame

Fonte: Elaborado pelas autoras.

A primeira estratégia do $N Y T$ é a produção de reportagens visuais e uso de ferramentas digitais. Nesse contexto, observa-se que a Exame aposta na produção diária de vídeos. Maurício Grego (2017), editor chefe do site Exame, explica que o vídeo é um elemento essencial para atrair a audiência. Os vídeos são publicados diariamente no site e a Exame tem um canal específico no Youtube para divulgar suas produções. "São mais ou menos quatro vídeos diários e logo cedo tem, normalmente, um de carreira, um de empreendedorismo, um de fianças pessoais e tem um sobre mercado financeiro que se chama Direto da Bolsa" (GREGO, 2017).

A questão do áudio também é abordada pela Exame, que utiliza esse recurso para oferecer reportagens em áudio para os leitores. O site e o aplicativo apresentam a possibilidade de matérias em áudio, já o impresso conta com o recurso do mobile view, que permite que o leitor, ao baixar o aplicativo Blippar, escute a reportagem sem precisar ler. Para isso, é preciso abrir a revista e posicionar a câmera do celular na primeira página da reportagem. Em seguida, o aplicativo identifica o conteúdo e começa a ler a notícia. 
Em relação ao uso de ferramentas digitais, a produção de notificações e newsletters são estratégias que aproximam a Exame do NYT. Além das atualizações em tempo real, a Exame envia por e-mail de segunda a sexta a newsletter com acontecimentos importantes para os usuários. No caso das notificações, elas aparecem na sessão "Às Sete" do aplicativo Exame Hoje. Os assinantes recebem alertas no celular às $7 \mathrm{~h}$ e às $19 \mathrm{~h}$ com informações relevantes para o começo e o fim do dia. Fagerlund explica, a importância do uso de e-mails e boletins informativos pelas empresas de mídia: "No mundo digital de hoje, os meios de comunicação precisam de todos os canais disponíveis para alcançar o público" (FAGERLUND, 2016, p. 5).

O uso de vídeos, newsletter e notificações são classificados como inovação tecnológica de produto e inovação organizacional. A Exame aplica a tecnologia para o desenvolvimento de produtos que engajam a audiência, como os vídeos, áudios e newsletters. Com isso, é necessário que os jornalistas se adaptem à produção desses formatos, alterando a estrutura organizacional. Por exemplo, o vídeo é utilizado no formato multimídia e, portanto, exige competências específicas dos jornalistas que, conforme a dimensão do trabalho, formam equipes multidisciplinares que modificam a estrutura trabalhista. No caso das newsletters e das notificações, observa-se um formato de produção que exige uma curadoria de informações. Portanto, a estrutura organizacional é alterada para que os jornalistas tenham tempo para realizar a curadoria e seleção das informações.

No caso da edição digital da revista constatou-se um baixo uso de reportagens visuais e interativas. A revista está disponível para os assinantes no site e no aplicativo, mas é apenas um PDF da revista impressa. As reportagens são copiadas do impresso integralmente, assim como imagens e gráficos. Não existe inserção de ferramentas digitais como gráficos interativos ou vídeos. O texto corrido, e muitas vezes longo, acaba se tornando cansativo. A escassez do uso de ferramentas digitais na revista digital atrapalha as estratégias de inovação da Exame e afeta a presença de uma percepção inovadora da marca pela audiência.

A próxima estratégia valorizada pelo $N Y T$ é a interação com os leitores para a produção de conteúdo informativo. O jornal incorpora a colaboração da audiência, que é fundamental no ecossistema digital. No relatório do Journalism That Stands Apart (2017), os jornalistas exemplificam a importância desse engajamento ao mostrar a produção do vídeo documentário Ladies First (LADIES..., 2016), em que mulheres da Arábia Saudita enviaram depoimentos contando sobre suas vidas. Com o monitoramento da revista Exame, percebe-se que a publicação tem uma baixa participação dos leitores. Os poucos casos que acontecem o envolvimento da audiência ocorrem pelos meios tradicionais (cartas ou e-mails). Na sessão 
"Cartas \& E-mails", os leitores enviam comentários e opiniões sobre acontecimentos das edições passadas. Porém, essa sessão não pode ser considerada uma estratégia de inovação porque o formato de interação remete a uma estrutura pré-web, com um modelo tradicional de colaboração. Os mesmos comentários são reproduzidos integralmente no site e no aplicativo.

No ambiente virtual existe um pequeno espaço de colaboração. Por exemplo, o canal "Seu Dinheiro", do site Exame, que apresenta dicas e responde questões de finanças. Abrantes (2018) explica que os leitores enviam por e-mail dúvidas sobre finanças pessoais que são respondidas por um especialista da área. Como observado na nota, "É melhor investir em um negócio ou em uma aplicação financeira?” (D’AQUINO, 2017), publicada em 15 de novembro de 2017, é feito um convite para público participar com perguntas. A dúvida do leitor é explicada por um especialista e ao final os usuários encontram o e-mail do canal para participarem, enviando seus questionamentos. Essa ação é classificada como uma inovação tecnológica porque altera o processo de trabalho do jornalista por meio da tecnologia e resulta em um produto noticioso que vai de encontro às necessidades do leitor. A estratégia também é classificada como inovação organizacional, uma vez que a Exame insere um novo método de produção, envolvendo a interação entre jornalistas e audiência.

As três plataformas (revista, site e aplicativo) da Exame apresentam pouca colaboração dos leitores nas produções das reportagens. A revista poderia investir em novos formatos colaborativos com a audiência, pensando em pautas que envolvessem os leitores por meio de ferramentas digitais, como faz o NYT. A análise infere que a interação é baixa e continua a acontecer pelos meios tradicionais como cartas e $e$-mails.

O relatório estudado mostra que o NYT aposta no desenvolvimento de novos produtos jornalísticos. Essa estratégia foi observada na Exame com o lançamento do aplicativo Exame Hoje, em abril de 2016. Em relação ao mercado nacional, ela foi a primeira revista informativa a desenvolver um aplicativo que entregasse para o leitor um conteúdo exclusivo, com informações diferentes da revista e do site. As notícias são focadas no aprofundamento e na análise, como acontece na sessão "Para Entender", por exemplo, que apresenta um conteúdo com maior profundidade e interpretação sobre um determinado tema. Dentro do aplicativo existe um espaço para os colunistas, que discutem assuntos de mercado, economia, comportamento, marketing, gestão e carreira, relativos às preferências do público da revista. Nomes como Paul Krugman, economista norte-americano e vencedor do Prêmio Nobel de Economia em 2008, e Celso Toledo, doutor em economia pela USP e diretor da LCA Consultores, agregam conhecimento especializado para o conteúdo produzido. 
Segundo Lucas Amorim (2017), redator chefe do aplicativo Exame Hoje, esse formato é inovador e a Exame foi a primeira no Brasil a implementá-lo. A revista percebeu a necessidade de levar a linguagem da publicação para o dia a dia dos leitores, por meio de plataformas mobile. O Exame Hoje registrou 48 mil assinantes e 2,8 milhões de pages views, segundo dados do IVC, em dezembro de 2017. Ainda de acordo com as informações do instituto de pesquisa, em agosto de 2016 o aplicativo tinha 32 mil assinantes. No período de um ano e quatro meses, a plataforma mobile ganhou 16 mil assinantes.

Quando a Exame insere um novo produto no mercado para atender as necessidades da audiência, desenvolve a inovação de marketing. O aplicativo Exame Hoje também se apropria da inovação tecnológica e organizacional. A ferramenta mobile é categorizada como inovação tecnológica de produto porque se apropria de tecnologias para o desenvolvimento de um novo produto. A questão organizacional acontece com a formação do terceiro núcleo da Exame, com jornalistas voltados para a produção de conteúdo exclusivo para o aplicativo. Essa nova configuração provoca alterações na rotina de trabalho e na estrutura organizacional da revista. Atualmente, a marca tem uma equipe exclusiva para a produção dos conteúdos do aplicativo.

A estratégia de redefinir o sucesso afeta o modo como a Exame enxerga o modelo de negócio. Costa (2014) afirma que o NYT introduziu o "Time Select”, em 2005, possibilitando a leitura do conteúdo para quem pagasse 50 dólares anuais. De acordo com o autor, a estratégia gerou 10 milhões de dólares por ano e 227 mil assinaturas para o jornal. Em 2007, o jornal abriu o conteúdo considerando que os anunciantes seriam as principais fontes de receita. "O jornal abandonara também a cobrança dos leitores internacionais. Entrou na fase na qual acreditava na publicidade como única saída possível para equilibrar as contas" (COSTA, 2014, p. 95). Porém, o resultado não foi positivo. Costa (2014) explica que o jornal perdeu 60\% dos anunciantes de 2000 para 2010 e precisou alterar o modelo de negócio. Com isso, o NYT aplicou o paywall poroso, oferecendo vinte conteúdos gratuitos e depois cobrando o valor mensal de US\$15. O resultado foi extremamente positivo, segundos dados divulgados pelo NYT em maio de 2018: no primeiro trimestre de 2018 teve um total de 2,783 milhões de assinantes digitais, no mesmo período de 2017 o número era de 308 mil assinaturas digitais (PIESER, 2018).

De acordo com o relatório de inovação do $N Y T$, as empresas jornalísticas precisam pensar em estratégias inovadoras para cobrar pelo conteúdo. Assim como no jornal internacional, a Exame também se apropria do paywall poroso. Em junho de 2017, a revista modificou o modelo de negócio oferecendo acesso a dez conteúdos por mês e ao atingir esse 
número os leitores precisam pagar $\mathrm{R}$ \$ 19,90 (nos três primeiros meses) e depois $\mathrm{R} \$ 29,90$. A estratégia faz parte de uma inovação de marketing porque a Exame reestruturou o modelo de negócio, aplicando uma ação de marketing (cobrança do conteúdo no site). A inserção do paywall em uma publicação tradicional como a Exame justifica a classificação da inovação, que passou a valorizar mais sua produção digital.

O NYT defende a importância de redações trabalhando em conjunto. O periódico acredita em uma equipe multiplataforma com produção para o impresso e digital. No entanto, a Exame não aplica essa estratégia organizacional. Atualmente, o veículo apresenta três redações independentes (revista, site e aplicativo). A segregação dos núcleos acontece para garantir uma melhor produtividade. Cada plataforma apresenta características próprias com formatos de produções específicos para cada meio. A equipe da Exame defende a importância da separação das redações para atender as características da revista, do site e do aplicativo. Não obstante, os editores consideram relevante a coesão e o diálogo entre as unidades. Contudo, observa-se que a Exame precisa ter uma relação mais próxima entre os núcleos, e por isso a publicação se prepara para uma possível unificação. De acordo com Talita Abrantes (2018), editora do site Exame, não se sabe como será esse processo de unificação, mas promoverá um maior diálogo entre as equipes. Flávia Furlan (2018), repórter da revista impressa, constata que quando isso acontecer, a estrutura organizacional da Exame será afetada, sendo necessário uma proximidade entre profissionais das mesmas editorias. Essa estratégia envolve inovação organizacional porque a divisão ou integração afeta a rotina de trabalho.

\section{CONSIDERAÇÕES}

$\mathrm{O}$ atual cenário do jornalismo exige que as empresas de comunicação invistam em inovações para garantir sustentabilidade. O NYT se destaca com sua atuação, sendo referência na transformação do jornalismo tradicional para o jornalismo digital. Os dados dos assinantes digitais apresentados neste artigo justificam o sucesso do periódico. A publicação dos relatórios de inovação indica a preocupação do periódico em olhar para o futuro e no pensamento estratégico da organização. O relatório Journalism That Stands Apart (2017) apresenta metas do NYT para 2020 e foi relacionado com as iniciativas da Exame para verificar as aplicações de inovação que já foram consolidadas fora do Brasil em uma publicação nacional. 
$\mathrm{Na}$ Exame, a estratégia de reportagens mais visuais e uso de ferramentas digitais se concentra na produção de vídeos, matérias em áudio e envio de newsletter. A possibilidade de o leitor do impresso escutar a reportagem revela a preocupação da marca em levar tecnologia e conteúdo para diversificar a audiência e promover inclusão digital. No entanto, é perceptível a falta de investimento no uso das ferramentas digitais para a criação de novos formatos e interação com a audiência. A edição digital da revista, por exemplo, é uma cópia integral da revista impressa. O engajamento da audiência é baixo e acontece por meio dos formatos tradicionais como cartas e e-mails. A Exame poderia explorar mais práticas utilizando ferramentas digitais para levar o leitor para dentro das reportagens e estabelecer uma conexão mais inteirada e constante.

Como inovação de marketing, a Exame alterou seu negócio ao inserir o paywall no site, produzindo uma nova estratégia de monetização. Em relação a outras publicações nacionais, a Exame se inova com a criação do aplicativo Exame Hoje. Nessa categoria, a marca desenvolveu um produto diferenciado, com informações voltadas para o seu nicho de mercado. O aplicativo entrega um conteúdo único, com explicações analíticas e aprofundadas que não aparecem nas outras plataformas da revista. Com isso, a Exame alterou os processos produtivos ao criar uma equipe exclusiva para esse produto.

A marca apresenta núcleos separados, mas com a possibilidade de integração. Nesse quesito, é interessante a percepção da Exame nas produções independentes para a otimização das produções. Porém, a falta de integração entre as redações afeta a sinergia e o diálogo entre os núcleos. Diante desse aspecto, a revista caminha para uma estratégia de inovação organizacional semelhante ao do NYT com a unificação das redações. A possibilidade de uma equipe única para a Exame apresenta aspectos positivos e negativos. A integração é interessante pelo ponto de vista estrutural, para que o jornalista não fique isolado, promovendo cooperação e diminuindo os custos. Consequentemente, acarreta o enxugamento da redação e o jornalista pode acabar sobrecarregado, interferindo na qualidade da produção. Com a unificação, o profissional precisa trabalhar em várias plataformas, o que pode comprometer a elaboração de um trabalho com maior foco, como acontece atualmente. Observa-se que a Exame está avaliando práticas organizacionais em seu modelo de negócio em busca de melhores alternativas. É importante que a marca, com ou sem integração, não deixe de pensar na audiência e nas especificidades de cada plataforma.

Por meio deste estudo, é perceptível um conjunto de tentativas de inovação da Exame, principalmente em termos de Brasil, porém não existe uma estratégia própria. A marca 
reproduz modelos de sucesso de veículos internacionais. Em comparação com o cenário nacional, ela está iniciando alguns movimentos que indicam inovação nas empresas jornalísticas, em especial no segmento de revistas informativas. É interessante perceber que, por se tratar de uma mídia tradicional, a Exame começou a quebrar algumas barreiras modificando e implementando novos produtos. Com isso, a marca promove mudanças organizacionais, tecnológicas e de marketing. O aplicativo Exame Hoje é um exemplo, uma vez que nenhuma revista nacional, até o momento de finalização deste estudo, utilizou um aplicativo neste formato. Ainda assim, a marca precisa investir em maiores inovações como a inserção da participação da audiência dentro de suas publicações e uma maior interação com os jornalistas.

Diante das ações pontuadas no relatório Journalism That Stands Apart (2017), nota-se que a Exame está em uma fase inicial no desenvolvimento de inovações. A publicação utiliza processos inovadores com relação ao que fazia anteriormente, mas ainda precisa se modernizar e investir mais no digital. Segundo Grego (2017), as publicações internacionais estão mais avançadas porque testam modelos de negócio. "Aqui no Brasil, a gente ainda está no começo, ainda estamos atrasados" (GREGO, 2017). As empresas de mídia brasileiras começaram a aplicar inovações tardiamente e isso é refletido pelas implementações estabelecidas na revista Exame. Dessa maneira, constata-se que a Exame reproduz modelos de inovação e negócios que já foram testados em outros mercados, exemplificado neste estudo com base nas estratégias do NYT, e os implementa nos setores organizacionais, de marketing e tecnológicos da empresa, mas ainda é necessário inovar de forma mais efetiva em processos, produtos e modelos de negócio para criar mercados e relações diferenciadas com a audiência para se sobressair no ambiente digital.

\section{REFERÊNCIAS}

ABRANTES, T. Entrevista concedida a Mariana Benvenido. São Paulo, 02 fev. 2018.

AMORIM, L. Entrevista concedida a Mariana Benvenido. São Paulo, 02 fev. 2017.

BARAÑANO, A. M. Gestão da inovação tecnológica: estudo de cinco PMEs portuguesas. Revista Brasileira de Inovação, Campinas, v. 4, n. 1, p. 57-96, jan./jun. 2005. Disponível em: https://periodicos.sbu.unicamp.br/ojs/index.php/rbi/article/view/8648907/15453. Acesso em: 16 abr. 2018. 
BAUMANN, S. Adapting to the Brave New World. In: STORSUL, T.; KRUMSVIK, A. H.; KÜNG, L.; DOGRUEL, L. (ed). Media Innovations: a multidisciplinary study of change. Gothenburg: Nordicom University of Gothenburg, 2013.

BOCZKOWSKI, P. Digitizing the news: innovation in online newspapers. Cambridge: MIT Press, 2004.

CAPRINO, Mônica (org.). Comunicação e Inovação. São Paulo: Paulus, 2008.

CHRISTENSEN, C. Be the disruptor. Nieman Reports, Cambridge, v. 66, n. 3, 2012.

COSTA, C. T. Um modelo de negócio para o jornalismo digital. Revista de Jornalismo da ESPM, São Paulo, n. 9, p. 51-115, 2014. Disponível em:

https://drive.google.com/file/d/0B17Kzd_mFtzrdVF4dEFQMnJWakE/edit. Acesso em: 15 jun. 2018.

D’AQUINO, C. É melhor investir em um negócio ou em uma aplicação financeira? Exame, São Paulo, 15 nov. 201. Disponível em: https://exame.abril.com.br/seu-dinheiro/e-melhor-investir-em-umnegocio-ou-em-uma-aplicacao-financeira/. Acesso em: 03 jun. 2018.

Editora Abril. Mídia Kit Revista Exame 2018. São Paulo, 2018. Disponível em:

<http://publiabril.abril.com.br/marcas/exame/plataformas/revista-impressa>. Acesso em:10 fev. 2018.

FAGERLUND, C. Back to the Future: email newsletters as a digital channel for journalism. London: London School of Economics and Political Science, 2016. Disponível em:

http://www.lse.ac.uk/media@1se/Polis/documents/Back-to-the-future---Email-Newsletters-as-a-

Digital-Channel-for-Journalism.pdf. Acesso em: 15 fev. 2018.

FONTOURA, M. C. Desafios do jornalismo: uma análise acadêmica do relatório de inovação do The New York Times. Revista Alceu, v. 16, p. 187-200, 2015. Disponível em:

https://www.academia.edu/31535088/Desafios_do_jornalismo_uma_an\%C3\%A1lise_acad\%C3\%AA mica_do_relat\%C3\%B3rio_de_inova\%C3\%A7\%C3\%A3o_do_The_New_York_Times. Acesso em: 10 jun. 2018.

FRANCISCATO, C. E. Uma proposta de incorporação dos estudos sobre inovação nas pesquisas em jornalismo. Estudos em Jornalismo e Mídia, Florianópolis, v. 7, n. 1, 2010. Disponível em: https://periodicos.ufsc.br/index.php/jornalismo/article/view/1984-6924.2010v7n1p8/12694. Acesso em: 30 fev. 2018.

FURLAN, F. Entrevista concedida a Mariana Benvenido. São Paulo, 31 jan. 2018.

GIL, A. C. Métodos e técnicas de pesquisa social. São Paulo: Atlas, 1994.

GREGO, M. Entrevista concedida a Mariana Benvenido. São Paulo, 02 fev. 2017.

GRUESKIN, B.; SEAVE, A.; GRAVES, L. The story so far: what we know about the business of digital journalism. New York: Columbia Journalism School, 2011.

GYNNILD, A. Journalism innovation leads to innovation journalism: the impact of computational exploration on changing mindsets. Sage, Thousand Oaks, v. 15, n. 6, p. 713-730, jul. 2014.

HIGGINS, J. M. Innovate or evaporate: test \& improve your organization's IQ, its innovation quotient. New York: New Management Publishing Company, 1995.

KÜNG, L. Innovation, technology and organizational change. In: STORSUL, T.; KRUMSVIK, A. H.; KÜNG, L.; DOGRUEL, L. (ed). Media Innovations: a multidisciplinary study of change.

Gothenburg: Nordicom University of Gothenburg, 2013. 
LADIES first: Saudi Arabia's female candidates. Produção de Mona El-Naggar e Adam Bolt. New York: The New York Times, 2016. Disponível em:

https://www.nytimes.com/video/world/middleeast/100000004711633/ladies-first-saudi-arabiasfemale-candidates.html. Acesso em: 23 jun. 2018.

LEONHARDT, D.; RUDOREN, J.; GALINSKY, J.; SKOG, K.; LACEY, M.; GIRATIKANON, T.; EVANS, T. Journalism That Stands Apart: the report of the 2020 group. New York Times, New York, jan. 2017. Disponível em: https://www.nytimes.com/projects/2020-report/index.html. Acesso em: 10 fev. 2018.

NAFRÍA, I. La reinvencion de The New York Times. Austin: University of Texas, 2017.

NAIDOO, V. Firm survival through a crisis: the influence of market orientation, marketing innovation and business strategy. Industrial Marketing Management, Amsterdam, v. 39, n. 8, p. 1311-1320, nov. 2010 .

OCDE. Manual de Oslo: diretrizes para coleta e interpretação de dados sobre inovação. Brasília, DF: Finep, 2006. Disponível em: http://www.finep.gov.br/images/apoio-e-financiamento/manualoslo.pdf. Acesso em: 20 jun. 2018.

PAVLIK, J. V. A tecnologia digital e o jornalismo: as implicações para a democracia. Brazilian Journalism Research, Brasília, DF, v. 7, n. 1, p. 94-118, 2011. Disponível em: https://bjr.sbpjor.org.br/bjr/article/view/340/314. Acesso em: 24 jun. 2018.

PAVLIK, J. V. Innovation and the future of journalism. Digital Journalism, v.1, n. 2, p. 181-193, 2013.

PEISER, J. New York Times Co. reports revenue growth as digital subscriptions rise. New York Times, New York, 3 maio 2018. Disponível em:

https://www.nytimes.com/2018/05/03/business/media/new-york-times-earnings.html. Acesso em: 10 jun. 2018.

PICARD, R. Criação de valor e o futuro das organizações jornalísticas: por que motivo e como o jornalismo deve mudar para se manter relevante no século XXI. Porto: Editora Media XXI, 2013.

SAAD, E. Inovação e empresas informativas: aliados, inimigos ou em permanente estado de “discussão da relação"? Revista Parágrafo, São Paulo, v. 4, n. 2, p. 73-87, jul./dez. 2016. Disponível em: http://www.revistaseletronicas.fiamfaam.br/index.php/recicofi/article/view/482/408. Acesso em: 15 jun. 2018.

SOUZA, P. C. F. Experiências de inovação no jornalismo digital: um estudo de caso do Jornal Nexo. Revista Parágrafo, São Paulo, v. 5, n. 1, p. 146-156, jan./jun. 2017. Disponível em: http://revistaseletronicas.fiamfaam.br/index.php/recicofi/article/view/504/524. Acesso em: 20 jun. 2018.

SPINELLI, E. M. Tipos de inovação nas empresas informativas e a relevância da dimensão social. Contemporânea, Salvador, v. 15, n. 1, p. 64-80, jan-abr. 2017. Disponível em: https://portalseer.ufba.br/index.php/contemporaneaposcom/article/view/21502/14434. Acesso em: 9 maio 2018.

VEÍCULOS mais admirados dobra painel. Meio \& Mensagem, São Paulo, 5 dez. 2016. Disponível em: https://www.meioemensagem.com.br/home/midia/2016/12/05/em-nova-edicao-veiculos-maisadmirados-dobra-painel.html. Acesso em: 20 jun. 2018.

WOLF, M. Teorias da Comunicação. Lisboa: Editora Presença, 2009. 
Doutora em Ciências da Comunicação pela Universidade de São Paulo (ECA/USP), mestre em Multimeios pela Universidade Estadual de Campinas (UNICAMP) e graduada em Comunicação Social (Jornalismo) pela Universidade Estadual de Londrina (UEL). É docente da Escola Superior de Propaganda em Marketing (ESPM) do curso de Graduação em Jornalismo e do Mestrado Profissional em Produção Jornalística e Mercado (MPPJM). Também é professora colaboradora do Programa de Pós-Graduação Stricto Sensu em Comunicação e Práticas de Consumo (PPGCOM/ESPM).

\section{Mariana Crosio Benvenido}

Mestre pelo programa de Mestrado Profissional em Produção Jornalística e Mercado (MPPJM/ESPM), graduada em Jornalismo pela Escola Superior de Propaganda e Marketing.

\section{(@) $\odot \otimes(-$}

Esta obra está licenciado com uma Licença

Creative Commons Atribuição-NãoComercial-CompartilhaIgual 4.0 Internacional 